\title{
Observed coupling of the mesosphere inversion layer to the thermal tidal structure
}

\author{
J. W. Meriwether, X. Gao \\ Department of Physics and Astronomy, Clemson University, Clemson, South Carolina \\ V. B. Wickwar, T. Wilkerson, K. Beissner, S. Collins' \\ Center of Atmospheric and Space Sciences, Utah State University, Logan, Utah
}

\author{
M. E. Hagan
}

NCAR High Altitude Observatory, Boulder, Colorado

\begin{abstract}
Rayleigh lidar observations of mesosphere temperature profiles obtained from 40 to $-100 \mathrm{~km}$ from Logan, Utah $(41.7,111.8 \mathrm{~W}$, altitude, $1.9 \mathrm{~km})$ over 10 nights in late February, 1995, revealed an interesting development between 60 to $75 \mathrm{~km}$ of a winter mesosphere inversion layer with an amplitude of $\sim 20-30 \mathrm{~K}$ and a downward phase progression of $\sim 1 \mathrm{~km} / \mathrm{hr}$. The data also showed two altitude regions exhibiting significant cooling of $10-30 \mathrm{~K}$ in extent. These were located below and above the peak of the inversion layer, respectively, at altitudes of $\sim 50-55 \mathrm{~km}$ and $\sim 70-80 \mathrm{~km}$. When these results were compared with the predictions of a global wave scale model (GSWM), the observed thermal mesosphere structure is similar to the computed composite tidal structure based upon the semi-diurnal and diumal tides with the exception that observed amplitudes of heating and cooling are $\sim 10 \mathrm{x}$ larger than predicted GSWM values. We suggest that these events over Utah are caused through a localized mechanism involving the coupling of gravity waves to the mesopause tidal structure.
\end{abstract}

\section{Introduction}

Explorations of the winter mesosphere thermal structure from 50 to $105 \mathrm{~km}$ with Rayleigh lidar [Hauchecorne et al., 1987], sodium temperature lidar [States and Gardner, 1998] and satellite remote sensing [Clancy et al., 1994, LeBlanc and Hauchecorne, 1997] have all detected an interesting feature of the thermal structure called the mesosphere inversion layer. It was first discovered in falling sphere observations by Schmidlin [1975]. The amplitude of the enhancement observed is typically $\sim 25 \mathrm{~K}$ but can be as high as $100 \mathrm{~K}$ [Meriwether et al., 1994]. The rate of occurrence is nearly continuous $(>85 \%)$ for winter but sporadic for summer $(<40 \%)$.

The physical mechanism producing the inversion layer structure is not well understood. Meriwether et al. [1994] using Rayleigh lidar observations conducted at the Wright Patterson Air Force base in Ohio found that the thermal structure for the inversion layer included long-period wave activity with downward phase propagation for winter events. Hence, one

'S. Collins, now at Arecibo Observatory, Box 995, Arecibo, PR 01613

Copyright 1998 by the American Geophysical Union.

Paper number 98GL00756.

0094-8534/98/98GL-00756\$05.00 could suppose that the inversion anomaly is simply the breaking of a slow-moving long-period inertio-gravity wave similar to those that have been seen frequently [Tsuda et al., 1990]. However, the extensive lidar observations reported by Dao et al.[1995] covering the entire range of altitudes from $25 \mathrm{~km}$ to $105 \mathrm{~km}$ established a link between the inversion layer and the diurnal tidal structure that is incontrovertible: three cycles of hot and cold perturbations 5 times larger than tidal amplitudes. The separations between maxima in the 40 to $70 \mathrm{~km}$ range were found to be $-22-24 \mathrm{~km}$, typical of the known vertical wavelength, $\sim 25 \mathrm{~km}$, for the propagating diurnal tide [Hays et al., 1994] at these altitudes.

Gravity wave activity appears to be an important part of the development of the inversion layer. Thomas et al.[1996] examined data from daytime radar detections of turbulent mesosphere layers and concluded that the inversion layer seen over Wales in their lidar profiles is adjoined to a region of shear instability. Sica and Thorsley [1996] reported lidar results indicating numerous vertically-thin regions characterized by a superadiabatic lapse rate and therefore convectively unstable.

A proposal to explain the inversion layer based upon gravity waves is the idea of turbulent heating caused by the continual overturning of breaking high frequency gravity waves [Hauchecorne et al., 1987, Whiteway et al., 1995] accompanied by convective cooling for the top side. But Lubken's measurements of the turbulent dissipation rate in the upper mesosphere [Lubken et al., 1993] suggest that not much thermal energy would be released in such events so the large temperature amplitudes observed in inversion layer events may signify more the convergence or divergence of heat transported by waves. Walterscheid and Schubert [1990] applied sophisticated numerical modelling techniques to the simulation of the overturning and breaking of a gravity wave with a horizontal scale of $300 \mathrm{~km}$ and found that the thermal cooling effects can be significant, as much as $\sim-30 \mathrm{~K}$.

The $\mathrm{Na}$ wind and temperature observations [States and Gardner, 1998] based upon $24 \mathrm{hr}$ coverage of mesopause winds and temperatures over Illinois clearly show the contributions made by the mesopause tides to the thermal structure observed between 80 and $105 \mathrm{~km}$. An extension of these results to the nighttime thermal structure between 60 and $80 \mathrm{~km}$ predicts an inversion layer would be observed between 20 and 24 hrs LT. These results also found that determination of the reference temperature profiles is affected by the incomplete sampling of the mesosphere thermal structure over $24 \mathrm{hrs}$. 
In this paper we present results on the mesosphere inversion layer seen over the Rocky Mountains for one interesting period in late February, 1995. Excellent weather made possible the continual observations of this feature over 10 nights between February 19, 1995 to March 1 1995. Typical amplitudes of the inversion layer observed were $-10-15 \%$, i.e., $20-35 \mathrm{~K}$.

\section{Instrumentation and Analysis}

Rayleigh lidar density observations in the zenith between altitudes of 45 and $100 \mathrm{~km}$ in the Rocky Mountains were made with a Nd:YAG laser transmitter that emitted $800-850 \mathrm{~mJ}$ pulses at a repetition frequency of $30 \mathrm{~Hz}$. The power aperture product was 3.4 watts $\mathrm{m}^{2}$, and clear-sky profiles of photocounts to altitudes $>90 \mathrm{~km}$ were obtained after integration of laser shots over one hr. Details regarding the lidar instrument and observatory are included in Wickwar et al. [1998].

Temperature profiles were retrieved through the application of the hydrostatic law and the ideal gas equation of state [Meriwether et al., 1994]. The starting altitude of the analysis is determined by using the altitude at which the ratio of noise to signal is $6 \%$, which typically was within the range of 80 $90 \mathrm{~km}$ for data averaged over one hour and smoothed over 3 $\mathrm{km}$. The top-side temperature required for the temperature analysis was selected from MSIS-E90 predictions, an empirical model describing seasonal and nightly variations of the middle atmosphere density and temperature structure [Hedin, 1991].

The global-scale wave model (GSWM) is a 2-dimensional, linearized, steady-state numerical tidal and planetary wave
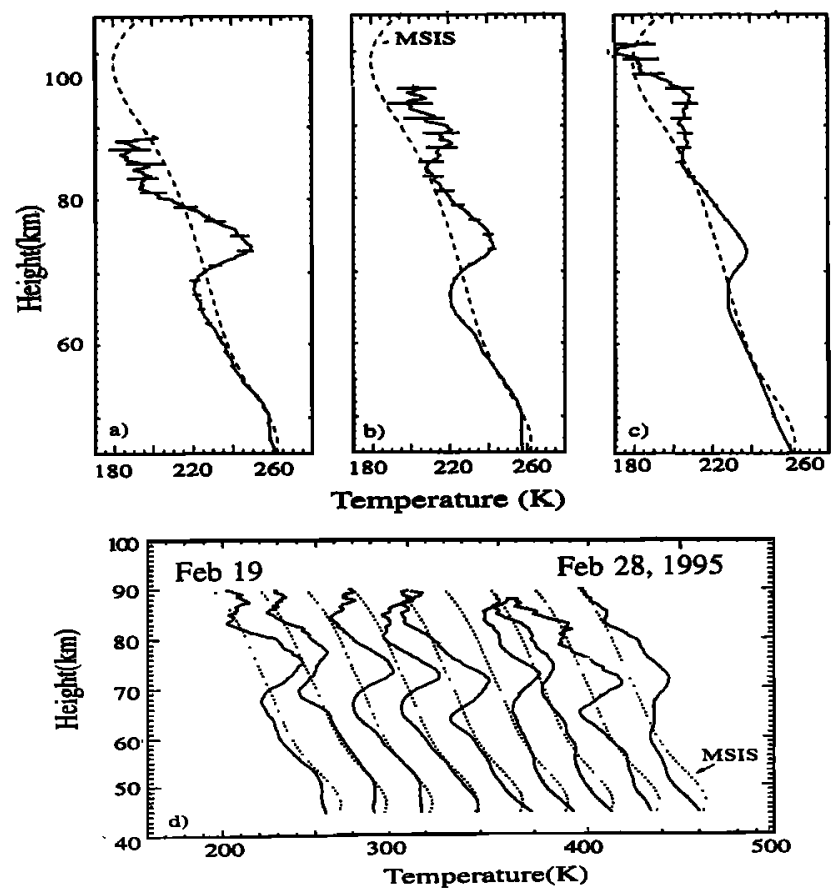

Figure 1. Examples of temperature profiles over Logan, Utah, for selected periods of averaging. The results were smoothed in altitude with a $3 \mathrm{~km}$ moving point average. The statistical errors of $\pm 1 \sigma$ are shown by horizontal lines spaced at $2.5 \mathrm{~km}$ intervals. Also shown for comparison (dashed line) is the MSIS profile. a) Hourly-profile, February 21, 1995, at 11 UT. b) Nightly-averaged profile for February 21, 1995. c) Monthly-averaged profile for February, 1995. d) Sequence of nightly-averaged profiles for nine February nights (19-27). model which extends from the ground to the thermosphere. GSWM resolves tidal perturbations using the extended and linearized Navier-Stokes equations and a background atmosphere that is defined by a series of empirical models of temperature, density, and zonal wind. Migrating tidal forcing is attributable to the absorption of solar radiation throughout the atmosphere and is parameterized in GSWM. Notably, GSWM tropospheric heating is based on 3-month average rates, so monthly tidal climatologies cannot be predicted using GSWM. The construction of this model also accounts for the effects of ion drag, molecular and eddy viscosity and conductivity, radiative damping, and gravity wave drag on the diurnal tide. Hagan [1996] and Hagan et al. [1993; 1995] provide further details.

Recent studies suggest that GSWM overestimates the effects of diumal tidal dissipation due to gravity wave stress during equinox [Geller et al., 1997] thereby underestimating the diurnal temperature response in the upper mesosphere and lower thermosphere by up to a factor of $\sim 2$. However, as will be discussed further, this GSWM tidal underestimate cannot account for the very large temperature perturbations associated with mesospheric inversion layers [Dao et al., 1995].

The latitudinal and altitudinal structure of the GSWM migrating diurnal and semidiurnal temperatures have been illustrated by Hagan [1996]. GSWM predicts that the tidal response over Logan Utah is dominated by the diurnal temperature cycle at altitudes below $60 \mathrm{~km}$ and by the semi-diurnal tidal mode variation above $75 \mathrm{~km}$. The interface region in between is where the GSWM model predicts an "inversion layer" featuring a temperature increase of $\sim 2-3 \mathrm{~K}$. This overall structure implies that the phase progression of the combined diurnal and semidiurnal temperature response will be consistent with the vertical structure of the diurnal tide.

\section{Results}

The persistence of the inversion layer over Utah during 10 nights totaling -90 hours of lidar observations is illustrated in Figure 1. Generally, the observing periods for these nights, February 19 - March 1, 1995 (no data on February 27), were 8 to 10 hours long. The panels a-c show examples of an hourlyaveraged profile (a) obtained at 11 UT on Febrtuary 21, 1995, a nightly-averaged profile (b) for February 21 , and a profile (c) based upon the average of all February observations. The MSIS-E90 model profile is also plotted to show for comparison the reference mesosphere thermal structure. Figure 1d plots the sequence of nightly-averaged profiles for the 9 February nights to illustrate the persistence and variability of the inversion layer during the continuous series of measurements. The inversion layer between 70 and $80 \mathrm{~km}$ is sharply delineated in Figure 1a and readily evident in the profiles of Figure $1 \mathrm{~b}$ and Figure 1d. Even for the monthly-averaged profile of Figure 1c, the inversion layer is obvious. Figure 1a shows that the statistical errors for the hourly-averaged profile were typically $\sim \pm 10 \mathrm{~K}$ at $88 \mathrm{~km}, \pm 2 \mathrm{~K}$ at $65 \mathrm{~km}$, and $<1 \mathrm{~K}$ at 50 to $55 \mathrm{~km}$. These errors are considerably smaller for the nightlyaveraged profiles. The monthly-averaged profile extended to $\sim 105 \mathrm{~km}$ and showed another layer at $\sim 97 \mathrm{~km}$ with a temperature enhancement also about $10 \%$, i.e. $\sim 25 \mathrm{~K}$. The data was carefully examined to look for possible signs of signalinduced noise but there was no indication of such problems.

The plots in Figure 1 a,b,c also depict two cold height sections below and above the inversion layer with amplitudes of 5 to $20 \mathrm{~K}$ relative to the MSIS reference. Another cold section 


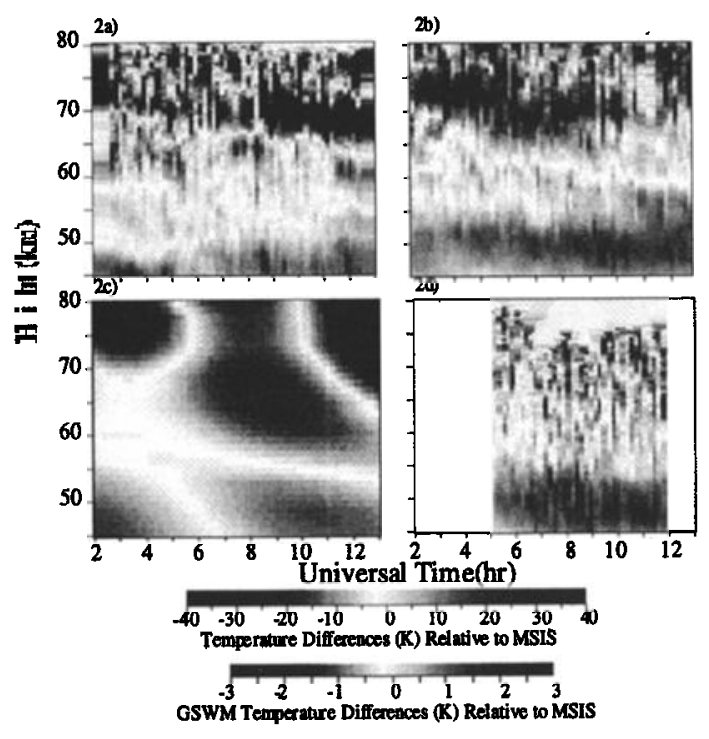

Figure 2. Rayleigh lidar height-time maps of temperature fluctuations at Logan, Utah for 2 active (top row) and 1 quiet nights compared with the GSWM predictions relative to MSISE90: a) February 20, b) February 28, c) GSWM results, and d) March 1, 1995.

appears below the stratopause $(<50-55 \mathrm{~km})$ with a cooling relative to the MSIS model of $\sim 10 \mathrm{~K}$.

These results encouraged us to examine temperature fluctuations, $\Delta \mathrm{Ts}$, for observations averaged over 10 minutes to look more closely at the diurnal altitude variations of heating and cooling regions during the night. To minimize possible aliasing problems, the approach adopted was to compute $\Delta \mathrm{T}$ values with respect to the MSIS-90 temperature model [Hedin, 1991]. Examples for three 1995 winter nights (February 20, February 28 , and March 1), of $\Delta \mathrm{T}$ results calculated by the relation $\Delta \mathrm{T}=$ $\mathrm{T}_{\text {Uath }}-\mathrm{T}_{\mathrm{MSIS}}$ are shown in Figure 2. For comparison, to quantify the expected magnitude of the tidal structure in Figures $2 a$, $2 \mathrm{~b}$, and $2 \mathrm{~d}$, the temperature differences calculated for the GSWM predictions of mesospheric tidal activity are presented in Figure $2 \mathrm{c}$ using the same format. Because only January and April GSWM climatological predictions were available, the April values were used. Differences between February and April GSWM-predicted values are small, $<1 \mathrm{~K}$. The model diurnal temperature amplitude may vary with season at $42^{\circ} \mathrm{N}$ by $1 \mathrm{~K}$ between 70 and $80 \mathrm{~km}$, and the semi-diurnal can vary by up to $2 \mathrm{~K}$ between 65 and $80 \mathrm{~km}$. There is little seasonal tidal variability below these altitudes. The rate of phase progression is seasonally invariant.

The $\Delta \mathrm{T}$ color shade plots in Figures $2 \mathrm{a}$ and $2 \mathrm{~b}$ for the two active nights of February 20 and February 28 depict a band of enhanced temperatures with a pattern of downward phase propagation and a phase speed of about $1 \mathrm{~km} / \mathrm{hr}$ between 60 and $75 \mathrm{~km}$ during the nighttime hours. Regions of negative $\Delta \mathrm{Ts}$ at $\sim 45-55 \mathrm{~km}$, each extending over $\sim 5 \mathrm{~km}$, are seen for times between 7 and 13 UT; there is also a band of depressed temperatures between 65 to $70 \mathrm{~km}$ for UT times of 7 to $13 \mathrm{hrs}$. The averaged amplitude of cooling is seen to be $-15-25 \mathrm{~K}$ or about $7-10 \%$ of the winter stratopause temperature. Thus, the valley-to-peak amplitude between 50 and $75 \mathrm{~km}$ can be as much as $\sim 30-50 \mathrm{~K}$. Such behavior suggests the possibility of a link between gravity wave activity generating the heating/cooling effects and the tidal thermal structure causing the downward trend of the inversion layer. In contrast, inspection of averaged profiles for 10 nights in August 1994 found no similar indications of heating or cooling relative to MSIS.

The inversion layer structure can change remarkably within 24 hours (cf. Figures $2 b$ and $2 d$ ). Here, the $10-\min \Delta T$ values for February 28 and March 1, 1995 showed the amplitudes of the inversion layer for March 1 to be much weaker and rather ill-defined with only sporadic heating episodes of positive $\Delta \mathrm{T}$ values, $\sim 10-15 \mathrm{~K}$.

\section{Discussion}

Except for the results reported by Dao et al. [1995], the behavior of the mesosphere inversion layer seen over Utah in these observations differs in two respects from the typical behavior reported in the literature. First, the perturbed thermal structure between 45 to $80 \mathrm{~km}$ exhibits a downward phase propagation for the inversion layer peak. The structural appearance of two regions of cooling below and above the inversion layer is suggestive of tidal structure similar to that predicted by the GSWM (cf. Fig $2 \mathrm{c}$ ) based upon a composite tidal structure representing contributions from the semi-diurnal and diurnal tidal components. Second, the amplitudes of the inversion layer and the two cold regions are quite large, typically a factor of 10 greater than the equivalent predicted tidal amplitudes [Hagan et al., 1995] of $\pm 2-3 \mathrm{~K}$.

We infer from the depictions of the inversion layer in Figure 2 that it is similar in form to the GSWM inversion layer located near altitudes of 60 to $75 \mathrm{~km}$ between 05 to $10 \mathrm{hrs}$ UT but linked with a more complex and disrupted tidal structure. If this identification is correct, then the key question is why the amplitudes for the hot and cold regions are ten times larger than the equivalent regions in the GSWM model? The calculations represented by the model of Forbes et al. [1991] have been refined and improved through subsequent developments [Hagan et al., 1996]. Tests based upon the comparison between the GSWM predictions and UARS observations [Geller et al., 1997] suggest that with the appropriate modification of the tidal dissipation component in the model to reflect the annual variation of gravity wave dissipation rates, the GSWM will capture the salient features of the global mesosphere tidal structure with reasonable fidelity. Hence, if the Utah inversion layer observations can be identified with an enhanced composite tidal structure, an explanation for the distortion of the thermal structure from the typical tidal structure must be found.

A coupling between breaking gravity waves and the mesosphere tidal structure [Walterscheid, 1981] could explain the large perturbations observed. This concept is based upon the idea of a critical layer in which the phase speed of the propagating gravity wave matches the combined speeds of the background mean wind and the tidal mode. When this occurs, either the convective or the shear instability causes wave energy to be transferred from the gravity wave to the mean flow with consequent changes in the tidal wind amplitude and phase. Enhanced diffusive heat transport would also be expected. A problem for this mechanism would be how the three cycles of enhanced tidal amplitudes seen in the Hawaiian data [Dao et al., 1993] can be explained. A possible test would be to quantify the flux of gravity waves into the mesosphere region and compare this measure, which might be the variance relative to the averaged thermal structure, with the extent that the amplitude of the inversion layer has developed for times of low and high wave activity.

Our results as well as those of States and Gardner 1998] illustrate a problem for the study of mesosphere thermal struc- 
ture whether from ground or space. If an inversion layer generated by tidal activity is not fully sampled over 24 hours, then aliasing would become serious in computing $\Delta T$ profiles. Such effects in deriving the perturbed thermal structure can be reduced by using the MSIS model as the reference profile required for the analysis. While some weak artifacts may appear, this approach does make possible the examination of the evolution of the major features of the $\Delta T$ structure throughout the night and from night to night.

To summarize, both the disturbed character of the temperature profile seen in the February nights, the development of 5 $8 \mathrm{~km}$ wide heating or cooling regions characterized by a vertical separation of $\sim 25 \mathrm{~km}$, the large magnitude of these differences relative to the GSWM predictions, the repetitive appearance and strong variability of this structure over 10 nights raise new questions as to the origins of the inversion layer. The similarity of the overall structure observed to the GSWM predictions with respect to phase progression and altitude separation of the cold regions suggests that mesosphere tidal activity combined with enhanced fluxes of gravity waves may influence the development of the inversion layer. The marked variation between the perturbed thermal structures for the two nights of February 28 and March 1 leads to the inference that when the gravity wave flux is reduced significantly, the amplitude of the inversion layer will diminish as well.

To improve our understanding of the physics of the forcing of the mesospheric tidal structure to produce the enhanced amplitudes observed, three requirements must be satisfied in future studies. The lidar altitude coverage needs to include several cycles of the diurnal tidal structure, i.e., $-25 \mathrm{~km}$ to $100 \mathrm{~km}$, to determine the vertical extent over which the coupling interactions might be taking place. Day and night observations averaged over several days are necessary to sample the mesosphere thermal structure properly to derive an accurate reference temperature profile free of aliasing effects. Finally, such measurements should feature not just improved temporal resolution of temperature profiles that giant lidar systems can provide but should also include mesosphere wind measurements to observe possible wind shear effects arising from the gravity wave-tidal structure coupling. Diffusive heat transport enhanced by convective or shear instability processes may cause the large amplitudes for the inversion layer reported here.

Acknowledgments. We are grateful to Chester Gardner and Hanli Liu for helpful comments. We thank John Maloney for technical and observational support. This research was supported by CEDAR NSF grants to Clemson University, Utah State University, and University of Maryland. The efforts of M. E. Hagan are supported by the NSF CEDAR program and NASA grant S-97239-E to NCAR

\section{References}

Clancy, R. Todd, D. W. Rusch, and M. T. Callan, Temperature minima in the average thermal structure of the middle mesosphere $(70-80$ $\mathrm{km}$ ) from analysis of 40-92 km SME global temperature profiles, $J$. Geophys. Res., 99, 19,001 - 19,020, 1994

Dao, P. D., R. Farley, Xin Tao, and C. S. Gardner, Lidar observations of the temperature profile between 25 and $103 \mathrm{~km}$ : Evidence of strong tidal perturbation, Geophys. Res. Letts., 1995
Forbes, J., M., J. Gu, and S. Miyahara, On the interactions between gravity waves and the diurnal propagating tide, Planet. Space Sci., 39, 1249-1257, 1991

Geller, M. A., Khattatov, B. V., V. A. Yudin, and M. E. Hagan, Modeling the diumal tide with dissipation derived from UARS/HRDI Measurements, Ann. Geophys., 15, 1198-1204, 1997.

Hagan, M. E., J. M. Forbes, and F. Vial, A numerical investigation of the propagation of the quasi 2-day wave into the lower thermosphere, $J$. Geophys. Res., 98, 23,193-23,205, 1993.

Hagan, M.E., Forbes, J. M., and Vial F., On modeling migrating solar tides, Geophys. Res.Lett., 22, 893-896, 1995.

Hagan, M. E., Comparative effects of migrating solar sources on tidal signatures in the middle and upper atmosphere, J.Geophys. Res.,101 21, 213-21,222, 1996.

Hauchecome, A., M. L. Chanin, and R. Wilson, Mesospheric temperature inversion and gravity wave breaking, Geophys. Res. Letts., 14, 935 - 936, 1987.

Hays, P. B., D.L. Wu, and the HRDI Science Team, Observations of the diurnal tide from space, J. Atmos. Sci., 51, 3077-3093, 1994.

Hedin, A. E., Extension of the MSIS thermosphere model into the middle and lower atmosphere, J. Geophys. Res., 96, 1159-1172, 1991.

Leblanc, Thierry and Alain Hauchecome, Recent observations of mesospheric temperature inversions, J. Geophys. Res., 102, 19471, 1997

Lubken, F.-J., W. Hillert, G. Lehmacher, and U. von Zahn, Experiments revealing small impact of turbulence on the energy budget of the mesosphere and lower thermosphere, J. Geophys. Res., 98, 20,36920,384, 1993

Meriwether, J. W. , P.D. Dao, R.T. McNutt, W. Klemetti, W. Moskowitz, G. Davidson, Rayleigh lidar observations of mesosphere temperature structure, J. Geophys. Res., 99, 16,973 - 16,987,1994

Schmidlin, F. J., Temperature inversions near 75 km, Geophys. Res. Letts., 3, 173-176, 1976.

Sica, R. J., and M. D. Thorsley, Measurements of superadiabatic lapse rates in the middle atmosphere, Geophys. Res. Letts., 23, 2797, 1996.

States, R. J. and C.S. Gardner, Influence of the diurnal tide and thermospheric heat sources on the formation of mesospheric temperature inversion layers, Geophys. Res. Letts., in press, 1998

Thomas, L., A.K.P. Marsh, D.P. Wareing, I.Astin, and H. Chandra, VHF echoes from the midlatitude mesosphere and the thermal structure observed by lidar, J. Geophys. Res., 101, 12,867-12,877, 1996.

Tsuda, T., S. Kato, T. Yokoi, T. Inoue, M. Yamamoto, T.E. VanZandt, S. Fukao, and T. Sato, Gravity waves in the mesosphere observed with the middle and upper atmosphere redar, Radio Science, 26, 10051018, 1990.

Walterscheid, R. L., Inertio-gravity wave induced accelerations of mean flow having an imposed periodic component: implications for tidal observations in the meteor region, J. Geophys. Res., 86, 9698 9706, 1981 .

Walterscheld, R.L., and G. Schubert, Nonlinear evolution of an upward propagating gravity wave: overturning, convection, transience and turbulence, J. Atmos. Sci., 47, 101 - 125, 1990.

Whiteway, J. A., A. I. Carswell, and W. E. Ward, Mesospheric temperature inversions with overlying nearly adiabatic lapse rate: An indication of a well-mixed turbulent layer, Geophys. Res. Letts., 22, 1201-1204, 1995.

Wickwar, V.B., K.C. Beissner, S. Elkington, S.C. Collins, T.D. Wilkerson, J. W. Meriwether, X.Gao, Mesospheric temperature profiles determined from Rayleigh lidar observations above Logan, Utah, in press, J. Geophys. Res., 1998

J. Meriwether, Department of Physics, Clemson University, Clemson,SC 2634-1911 (e-mail john.meriwether @ ces.clemson.edu)

K. Beissner, S. Collins, V. B. Wickwar, T. D. Wilkerson, Center of Atmospheric and Space Physics, Utah State University, Logan, Utah M. Hagen, National Center of Atmospheric Research, Box 3000, Boulder, CO 80307-3000

(Received December 10, 1997; revised February 17, 1998; accepted February 19, 1998) 